\title{
FOTODEGRADAÇÃO DE HIDROCARBONETOS POLICÍCLICOS AROMÁTICOS EM PLACAS DE SÍLICA IMPREGNADAS COM DIÓXIDO DE TITÂNIO
}

Laura Furquim Werneck Xavier e Isabel Maria N. S. Moreira

Departamento de Química, Pontifícia Universidade Católica do Rio de Janeiro, Rua Marques de São Vicente, 225, 22453-900 Rio de Janeiro - RJ

\section{Martha M. Higarashi e Josino C. Moreira*}

Centro de Estudos da Saúde do Trabalhador e Ecologia Humana, Escola Nacional de Saúde Pública-Fundação Oswaldo Cruz, Av. Brasil, 4365, 21041-210 Rio de Janeiro - RJ

Luiz Filipe V. Ferreira e Anabela S. Oliveira

Centro de Química-Fisica Molecular, Complexo Interdisciplinar, Instituto Superior Técnico, Av. Rovisco Pais, 1049-001, Lisboa - Portugal

\begin{abstract}
PHOTODEGRADATION OF POLYCYCLIC AROMATIC HYDROCARBONS (PAHs) ADSORBED ONTO SILICA GEL CHROMATOGRAPHIC PLATES IMPREGNATED WITH $\mathrm{TiO}_{2}$. Photodegradation of the PAHs anthracene, chrysene and benzo[k]fluoranthane on silica gel impregnated with $\mathrm{TiO}_{2}$ and over glass plates holding $\mathrm{TiO}_{2}$ was studied. Silica gel plates holding these substances were exposed to solar radiation, developed with hexane and photographed under ultra-violet light. The plates containing benzo[k]fluoranthene were also analysed by both diffuse reflectance and laser induced fluorescence. Diffuse reflectance spectra of the fluorescent spot from non irradiated plates showed small differences when compared with those obtained from irradiated plates. These spectral differences are compatible with formation of less conjugated compounds during irradiation. Fluorescence and time resolved fluorescence spectra observed after irradiation were identical to those obtained with benzo[k]fluoranthene in methanol. On plates holding silica, PAH degradation requires longer periods of solar irradiation when compared with those plates containing silica impregnated with $\mathrm{TiO}_{2}$. Glass plates impregnated with $\mathrm{TiO}_{2}$ also showed very rapid PAH degradation.
\end{abstract}

Keywords: PAH; photodegradation; thin layer chromatography.

\section{INTRODUÇÃO}

Os hidrocarbonetos policíclicos aromáticos (HPAs) são contaminantes ubíquos, formados em processos de combustão incompleta de matéria orgânica. $\mathrm{O}$ interesse no estudo da contaminação ambiental por essas substâncias está diretamente relacionado com suas propriedades biológicas, pois, vários componentes deste grupo apresentam propriedades carcinogênicas/mutagênicas ${ }^{1-3}$.

Devido aos riscos à saúde representados por estas substâncias, metodologias para descontaminação das matrizes ambientais contaminadas têm sido demandadas. Entre os métodos estudados para degradação de poluentes orgânicos, os processos oxidativos avançados (POAs) têm se destacado por suas elevadas capacidades de destruição, que se processam através de uma série de reações químicas e não apenas de transferência de fase e por suas aplicabilidades em grande número de matrizes ${ }^{4}$.

Os POAs baseiam-se na formação de radicais hidroxilas ${ }^{5,6}(\bullet \mathrm{OH})$ altamente oxidantes $\left(\mathrm{E}^{\mathrm{o}}=2,8 \mathrm{~V}\right)$ e capazes de reagir com praticamente todas as classes de compostos orgânicos e inorgânicos podendo levar à formação de intermediários mais biodegradáveis e, por vezes, à mineralização total dos poluentes ${ }^{4}$. Alguns semicondutores, dentre os quais o dióxido de titânio, têm sido muito utilizados nestes processos. Estas substâncias possuem a banda de valência (BV) eletronicamente completa e a banda de condução (BC) com estados de energia vazios. A absorção de fótons com

\footnotetext{
*e-mail: josinocm@fiocruz.br
}

energia suficiente resulta na promoção de elétrons da banda de valência para a banda de condução, com geração de lacunas $(\mathrm{h}+)$ na banda de valência. Estas lacunas possuem potenciais muito positivos que variam de 2,0 a $3,5 \mathrm{~V}$, valores suficientes para produzirem radicais $\bullet \mathrm{OH}$ a partir de moléculas de água adsorvidas na superfície do semicondutor. Os $\bullet \mathrm{OH}$ produzidos poderão reagir com qualquer material presente no sistema como, por exemplo, substâncias orgânicas de interesse (mecanismo indireto). Alternativamente, a lacuna fotogerada $(\mathrm{h}+)$ pode atuar como oxidante através da recepção de elétrons.

A fotocatálise tem sido proposta para descontaminação de matrizes ambientais e tratamento de resíduos industriais em laboratório. Sauer ${ }^{7}$ e co-autores estudaram a fotodegradação de uma mistura de tolueno-clorocarbono no ar. Tapalov ${ }^{8}$ e colaboradores trataram água contendo fungicidas utilizando a fotocatálise em suspensão aquosa de $\mathrm{TiO}_{2}$. Gálvez ${ }^{9}$ e colaboradores montaram um processo para detoxificação de água industrial utilizando placas fotoelétricas como fonte de radiação UV necessária para o início da fotocatálise; Oliveira ${ }^{10}$ e co-autores utilizaram a técnica de reflectância difusa para estudar a fotodegradação de HPA particulado na atmosfera urbana. Pramauro ${ }^{11}$ e colaboradores e Mallakin ${ }^{12}$ e co-autores estudaram, respectivamente, a fotodegradação de naftaleno e antraceno.

A cromatografia em camada fina é um método analítico amplamente utilizado na separação de matrizes e misturas complexas ${ }^{13}$. Além de seu poder de separação, a cromatografia em camada fina apresenta grande área superficial e algumas técnicas oferecem inclusive a possibilidade de concentrar amostras em zonas de con- 
centração diretamente sobre a placa cromatográfica. Como não existe solução de continuidade entre a zona de concentração e a camada de separação, ou seja, ambas estão em contato direto, isso permite que uma amostra possa ser concentrada e posteriormente separada na mesma placa cromatográfica. Os hidrocarbonetos policíclicos aromáticos estão entre as substâncias separáveis por esta técnica. O comportamento cromatográfico de vários HPAs em placas de sílica-gel é descrito por Bodzek ${ }^{14}$, Inscoe ${ }^{15}$ e Seiffert ${ }^{16}$.

Este trabalho reporta os resultados obtidos no estudo da eficiência de uma camada de dióxido de titânio depositado sobre a sílica constituinte da zona de concentração de uma placa de cromatografia em camada fina, na destruição de alguns HPAs (antraceno, criseno e benzo[k]fluoranteno), bem como a eficiência da camada de separação, também de sílica, no estudo do processo fotolítico.

A estrutura química dos três HPAs estudados é mostrada na Figura 1.

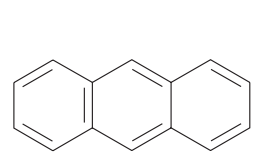

Antraceno

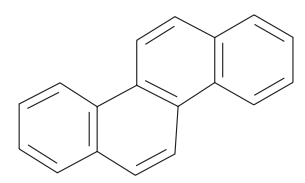

Criseno

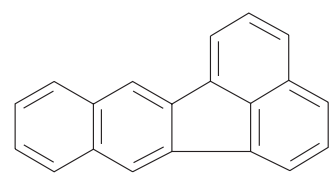

Benzo[k]fluoranteno

Figura 1. Estrutura química dos HPAs estudados neste trabalho

\section{PARTE EXPERIMENTAL}

\section{Reagentes e procedimentos}

Todos os solventes utilizados foram de grau para cromatografia. Dióxido de titânio P25 Degussa contendo $70 \%$ na forma anatase, área superficial BET $\left(50 \pm 15 \mathrm{~m}^{2} \mathrm{~g}^{-1}\right)$ e tamanho médio de partícula de $30 \mu \mathrm{m}$ foi utilizado em todos os experimentos que envolviam a presença deste fotocatalisador. Os padrões dos HPAs e seus similares deuterados foram da AccuStandart. Placas cromatográficas de sílica-gel, com zona de concentração também de sílica, sem indicador de fluorescência, de $20 \mathrm{~cm}$ x $20 \mathrm{~cm}$ e divididas em 20 raias de 1,0 cm cada, LK50 Linear K - Whatman foram utilizadas.

As soluções padrão de antraceno, criseno e benzo[k]fluoranteno na concentração de $1 \mathrm{mmol} / \mathrm{L}$ foram preparadas em diclorometano (DCM).

\section{Preparo da emulsão de dióxido de titânio}

A emulsão de dióxido de titânio utilizada foi preparada ${ }^{17}$ adicionando-se num almofariz 12,00 g de dióxido de titânio, 4 mL de água destilada e $0,4 \mathrm{~mL}$ de acetilacetona, misturando-se até se obter uma pasta homogênea. Em seguida, foram acrescentados 25 $\mathrm{mL}$ de água destilada e $0,2 \mathrm{~mL}$ de Triton $\mathrm{X}-100$. A mistura foi agitada por 20 min e conservada em frasco âmbar.

\section{Preparo das placas de sílica-gel}

No estudo da fotocatálise heterogênea, as zonas de concentração das placas cromatográficas de sílica-gel foram impregnadas por imersão na emulsão de dióxido de titânio e, a seguir, secas à temperatura ambiente por $24 \mathrm{~h}$ e envoltas em papel de alumínio. As zonas de concentração são formadas por sílica com baixa capacidade de adsorção e grande poder de absorção.

\section{Preparo das lâminas de vidro}

Lâminas de vidro para microscopia Corning com espessura entre 0,8-1,1 mm e com uma das faces esmerilhada foram recobertas com a emulsão de dióxido de titânio, envoltas em papel de alumínio e postas para secar por $24 \mathrm{~h}$.

\section{Irradiação dos HPAs}

Para esta etapa foram aplicados $10 \mu \mathrm{L}$ da solução padrão de benzo[k]fluoranteno sobre as zonas de concentração contendo o $\mathrm{TiO}_{2}$ em seis placas de sílica-gel, numeradas de 1-6. Uma das placas foi guardada no escuro e serviu como controle do experimento, as demais foram expostas à radiação solar. Todos os experimentos foram realizados no Campus da Fundação Oswaldo Cruz, Rio de Janeiro, no mês de agosto de 2001 e tiveram início às 10:00 h. O tempo de exposição à luz solar foi de até $120 \mathrm{~min}$. Todos os experimentos foram realizados em dias ensolarados e com pouca ou nenhuma nebulosidade. Transcorrido os tempos de exposição desejados, as placas foram introduzidas em uma cuba cromatográfica contendo aproximadamente $100 \mathrm{~mL}$ de n-hexano e, após desenvolvimento, fotografadas sob irradiação com luz UV $(\lambda=356 \mathrm{~nm})$. Sob estas condições, os HPAs estudados revelam-se através de uma emissão fluorescente azul-esverdeada, observada sobre um fundo azul escuro. As fotografias foram obtidas através do uso de um sistema U.V. Reprostar 3 - Camag com o filme Polaroid Studio 125 Película Instantânea Iso $125 / 22^{\circ} 8,5 \times 10,8 \mathrm{~cm}$. Estas placas foram posteriormente analisadas por refletância difusa e por fluorescência induzida por laser, no Laboratório de Fotoquímica de Superfícies do Centro de Química Física Molecular do Instituto Superior Técnico, Lisboa - Portugal. Os espectros de absorção no estado fundamental, na região do UVVis, de todas as manchas observadas nas placas cromatográficas foram registrados usando um espectrofotômetro OLIS 14 UV/Vis/NIR equipado com um acessório de reflectância difusa. A esfera integradora utilizada tem $90 \mathrm{~mm}$ de diâmetro interno e está revestida internamente com um material padrão banco $(\mathrm{R}=1)$, o qual recolhe de forma eficiente toda a luz dispersa pela amostra. $\mathrm{O}$ equipamento utilizado foi modificado de modo a permitir o uso de filtros de "cuton" apropriados, que impedem que a fluorescência da amostra atinja o detector. A reflectância das placas foi medida numa área de $\sim 2 \mathrm{~cm}^{2}$. A calibração prévia do sistema de coleta da luz foi realizada com padrões de branco (óxido de magnésio, Aldrich 99,9\%) e de preto (carbon black, Cabot 2000), os quais, no intervalo de 200 a $1000 \mathrm{~nm}$ têm reflectâncias da ordem de $97-98 \%$ e de $1-2 \%$, respectivamente.

Os ensaios de fluorescência induzida por lazer foram realizados à temperatura ambiente, usando geometria de reflexão. Um diagrama do sistema de luminescência induzida por laser é apresentado na ref. 10. Este sistema utiliza um impulso de 337,1 nm (adequado para a excitação de HPAs) de um laser de nitrogênio (Photon Technology Instruments, Model 2000, 600 ps FWHM, 1.3 mJ/impulso) como sistema de excitação, acoplado com um sistema de detecção ICCD, Oriel modelo Instapec V e um espectrógrafo Oriel modelo FICS 77440. Detalhes sobre a aplicação destas técnicas podem ser encontrados na ref. 10 e referências aí citadas.

Nos experimentos de fotodegradação de uma mistura de antraceno, criseno e benzo(k)fluoranteno, utilizou-se $20 \mu \mathrm{L}$ de uma solução, preparada misturando-se volumes iguais $(1 \mathrm{~mL})$ das soluções-padrão dos 3 HPAs, depositada sobre as zonas de concentra- 
ção de 10 raias de sílica-gel impregnadas com dióxido de titânio e numeradas de T1 a T10.

O controle do processo fotocatalítico foi feito de maneira semelhante, ou seja, as soluções-padrão dos HPAs foram aplicadas na zona de concentração de 10 raias de sílica-gel numeradas de S1 a S10, não impregnadas com dióxido de titânio.

Em cada experimento, uma das raias foi mantida no escuro e as demais foram expostas à radiação solar, como indicado no item anterior. Após exposição ao sol, todas as placas foram submetidas ao desenvolvimento cromatográfico e fotografadas.

Para verificar a influência da sílica-gel no processo fotocatalítico, $20 \mu \mathrm{L}$ da solução-padrão dos HPAs foram aplicados em seis lâminas de vidro cobertas com a emulsão de dióxido titânio. As placas foram expostas à radiação solar e uma delas foi mantida no escuro.

\section{Extração dos HPAs das placas de sílica-gel impregnadas com dióxido de titânio}

Os HPAs foram extraídos das fases estacionárias com o auxílio de $15 \mathrm{~mL}$ de DCM. Nestes casos, a mistura foi colocada sob agitação, por 2 h, em um agitador mecânico, filtrada com o auxílio de um funil de vidro e um chumaço de algodão e guardada em um frasco âmbar. Com o auxílio de uma seringa onde a agulha foi trocada por uma unidade filtrante de polietileno com membrana de PTFE não estéril de $0,22 \mu \mathrm{m}$ de poro e $13 \mathrm{~mm}$ de diâmetro, FEMEA $\mathrm{SLIP}^{\circledR} /$ Millipore, a solução foi retirada do frasco.

Esta alíquota filtrada foi evaporada sob fluxo de $\mathrm{N}_{2}$ e transferida com o auxílio de uma pipeta Pasteur para um balão volumétrico de $1 \mathrm{~mL}$. O frasco foi lavado três vezes com DCM para total transferência das substâncias extraídas e a solução final foi transferida para um frasco, onde foram acrescentados os padrões internos deuterados de naftaleno, acenafteno, fenantreno, criseno e perileno. Depois de identificada, a solução foi guardada sob refrigeração para ser analisada posteriormente por Cromatografia Gasosa/ Espectrometria de Massas (CG-EM).

As condições analíticas utilizadas na análise cromatográfica foram as seguintes: CG-EM Feneçam MAT GCQ Filos com cromatográfico Finningan 9001; coluna cromatográfica capilar J\&W scientific, tipo DB-XLBITD (alta resolução) com $30 \mathrm{~m}$ de comprimento e $0,25 \mathrm{~mm}$ de diâmetro interno e revestida internamente com filme de 0,25 $\mu \mathrm{m}$; gás carreador - Hélio; temperatura da fonte: $225^{\circ} \mathrm{C}$, impacto eletrônico: $70 \mathrm{eV}$, temperatura do injetor: $270{ }^{\circ} \mathrm{C}$, modo de injeção: split, razão $1 / 10$, volume de injeção $4 \mu \mathrm{L}$, programação: $35^{\circ} \mathrm{C}$ - isoterma de $1 \mathrm{~min}, 35-80{ }^{\circ} \mathrm{C} 40^{\circ} \mathrm{C} / \mathrm{min}, 80-$ $290,6{ }^{\circ} \mathrm{C} / \mathrm{min}, 290{ }^{\circ} \mathrm{C}$ - isoterma de $15 \mathrm{~min}$.

\section{RESULTADOS E DISCUSSÃO}

Os estudos preliminares sobre a separação cromatográfica de uma mistura contendo antraceno, criseno e benzo[k]fluoranteno (Figura 1) foram realizados em um sistema constituído por cromatofolhas de síilica-gel (Merck) e n-hexano. A ordem dos $R_{f}$ obtida nestes experimentos foi: antraceno $>$ criseno $>$ benzo(k)fluoranteno. Tomando-se o valor do $\mathrm{R}_{\mathrm{f}}$ do antraceno como padrão $\left(\mathrm{R}_{\mathrm{f}}=\right.$ $1,00)$, os valores dos $R_{f}$ relativos foram 0,85 para o criseno e 0,80 para o benzo(k)fluoranteno, indicando superposição parcial das manchas destes dois HPAs neste sistema.

\section{Fotodegradação do benzo[k]fluoranteno}

O desenvolvimento cromatográfico das placas impregnadas com dióxido de titânio contendo benzo[k]fluoranteno em tempos variá- veis de exposição ao sol mostrou a presença de uma única mancha fluorescente, cujo $\mathrm{R}_{\mathrm{f}}$ diminui com o aumento do tempo de irradiação, como mostrado na Tabela 1. Não foi observada nenhuma variação significativa no espectro de fluorescência obtido até 120 min de exposição ao sol, tempo máximo estudado, a não ser na intensidade da emissão. Após 10 min de exposição, a intensidade da emissão fluorescente apresentou um ligeiro aumento inicial seguida de um decréscimo para tempos mais longos.

Tabela1. Variação dos valores de $\mathrm{R}_{\mathrm{f}}$ do benzo[k]fluoranteno com o tempo de irradiação

\begin{tabular}{ccc}
\hline $\begin{array}{c}\text { Número da placa com } \\
\text { dióxido de titânio }\end{array}$ & $\begin{array}{c}\text { Tempo de exposição } \\
\text { ao sol (min) }\end{array}$ & $\mathrm{R}_{\mathrm{f}}$ \\
\hline 1 & 0 & 0,60 \\
2 & 10 & 0,56 \\
3 & 30 & 0,48 \\
4 & 60 & 0,43 \\
5 & 90 & 0,40 \\
6 & 120 & 0,36 \\
\hline
\end{tabular}

Nenhuma outra substância fluorescente foi evidenciada na camada de sílica-gel (zona de separação) nas análises por reflectância difusa ou por fluorescência induzida por laser. Em todos os experimentos, a mancha observada apresentava espectro de refletância difusa equivalente ao espectro de absorção do benzo[k]fluoranteno em metanol.

Os espectros de reflectância difusa das placas não irradiadas apresentaram ligeiras diferenças quando comparados aos espectros das placas irradiadas (Figura 2). Estas diferenças traduzem-se numa ligeira diminuição da banda de absorção detectada, a comprimentos de onda superiores a $400 \mathrm{~nm}$, acompanhada de um aumento da banda de absorção detectada na zona de menores comprimentos de onda $(<355 \mathrm{~nm})$. Estas modificações espectrais são compatíveis com a degradação do benzo(k)fluoranteno e conseqüente formação de compostos com menor conjugação (responsável pelo enchimento do espectro na zona de menores comprimentos de onda).

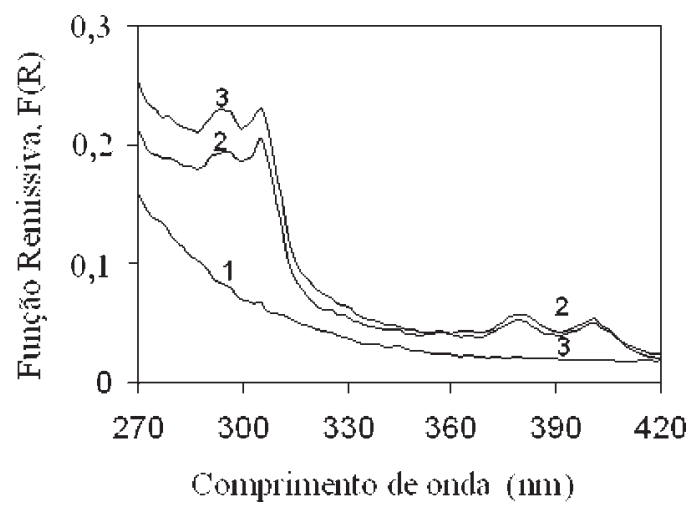

Figura 2. Espectros de reflectância difusa do benzo(k)fluoranteno. 1 - placa sem benzo(k)fluoranteno; 2 - placa com benzo(k)fluoranteno não irradiada; 3 - placa com benzo(k)fluoranteno com 120 min. de irradiação

Os espectros de fluorescência e de fluorescência resolvidos no tempo das manchas fluorescentes de todas as placas foram idênticos àqueles do benzo[k]fluoranteno em metanol (Figura 3).

As zonas de concentração, impregnadas com dióxido de titânio, não puderam ser avaliadas por estas técnicas, uma vez que o $\mathrm{TiO}_{2}$ absorve luz nesta região espectral. 

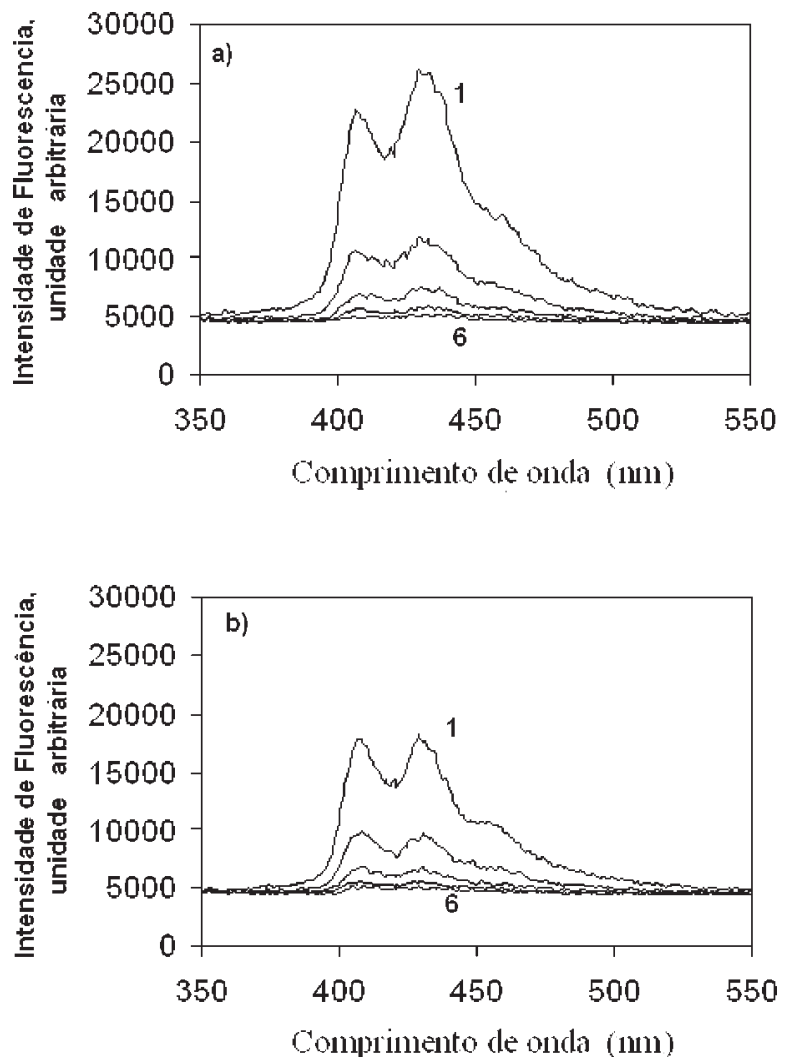

Figura 3. Espectros de fluorescência resolvida no tempo para a fotodegradação de benzo(k)fluoranteno. Curvas 1, 2, 3, 4, 5 e 6 foram registradas a, respectivamente, $0,5,10,15,20$ e 25 ns após o pulso do laser. a) placa não irradiada e b) placa com 120 min de exposição ao sol

Estes resultados são compatíveis com o mecanismo sugerido para a fotodegradação de HPAs, que envolve inicialmente a formação de um produto resultante da introdução de radicais hidroxilas na molécula do HPA, com aumento da polaridade da molécula sem significativo efeito sobre a fluorescência ${ }^{11}$.

\section{Fotodegradação de uma mistura de antraceno, criseno e benzo[k]fluoranteno}

\section{Análise qualitativa}

Estudos qualitativos foram realizados em placas expostas à radiação solar por tempos de 0 até $300 \mathrm{~min}$.

A revelação das placas de sílica sem impregnação com $\mathrm{TiO}_{2}$ mostra que, na ausência deste óxido, a degradação se processa muito lentamente. De fato, uma diminuição da intensidade da fluores- cência só pode ser notada visualmente após 180 min de exposição à luz solar.

A revelação das placas de sílica impregnadas com dióxido de titânio mostra uma degradação muito mais rápida. Inicialmente verificou-se o aumento da intensidade da fluorescência após $5 \mathrm{~min}$ de exposição à luz solar. Esta fluorescência diminui a partir dos 10 min até o final do experimento, quando é, comparativamente, desprezível.

Nas placas de sílica contendo dióxido de titânio, a partir de 20 min de irradiação pode-se verificar o aparecimento de uma mancha de coloração amarela, próxima ao ponto de aplicação da amostra. Esta coloração amarela aumenta com o tempo de exposição e é mais intensa quanto menor for a fluorescência emitida pelos HPAs.

Todas estas observações são compatíveis com o mecanismo sugerido por Pramauro ${ }^{11}$ para a degradação dos hidrocarbonetos policíclicos aromáticos (HPAs) que sugere a introdução de radicais $\cdot \mathrm{OH}$ na molécula do HPA, como fase inicial, e a formação posterior de quinonas. Sabidamente estes compostos possuem cor amarelada e têm maior afinidade pela fase estacionária utilizada que os HPAs.

A presença de antraceno só foi observada nas placas reveladas imediatamente após o desenvolvimento cromatográfico. Placas mantidas no escuro e à temperatura ambiente, observadas $24 \mathrm{~h}$ depois, não apresentavam a fluorescência característica deste composto, sugerindo perda por volatilização.

\section{Análise quantitativa}

Após serem extraídos das placas, os HPAs foram analisados quantitativamente por CG-EM. Os resultados podem ser encontrados na Tabela 2.

A análise destes resultados mostra que nas placas cromatográficas que continham apenas sílica, a diminuição da concentração do antraceno na sílica é rápida, porém, é bem pequena para criseno e benzo[k]fluoranteno, que é percebida apenas após longo tempo de irradiação (180 min). Já nas raias de sílica impregnadas com dióxido de titânio, a degradação dos três HPAs é mais rápida e bem nítida.

Os baixos valores de concentração de antraceno encontrados, além da degradação, podem envolver também perdas por volatilização.

Nas placas impregnadas com $\mathrm{TiO}_{2}$, aparentemente este inibe a volatilização permitindo observar a fotodegradação do antraceno.

Aparentemente, maior eficiência de degradação foi observada nas placas de vidro recobertas com dióxido de titânio. Entretanto deve ser considerado que a camada de dióxido de titânio depositada sobre as placas de vidro é bastante fina e com baixa capacidade de ad/absorção quando comparadas com a sílica-gel. Sendo assim, perdas das substâncias mais voláteis (antraceno) durante o experimento podem ter também contribuído, originando os baixos valores encontrados.

Tabela 2. Percentagem relativa de antraceno (ANT), criseno(CRI) e benzo[k]fluoranteno (BZK) nas placas de sílica gel após exposição à luz solar

\begin{tabular}{|c|c|c|c|c|c|c|c|c|c|}
\hline \multirow[t]{2}{*}{$\begin{array}{l}\text { Tempo de } \\
\text { exposição } \\
\text { ao sol (min) }\end{array}$} & \multicolumn{3}{|c|}{$\begin{array}{c}\text { Concentração nas placas } \\
\text { de sílica não impregnada } \\
(\%)\end{array}$} & \multicolumn{3}{|c|}{$\begin{array}{l}\text { Concentração em sílica } \\
\text { impregnada com dióxido } \\
\text { de titânio }(\%)\end{array}$} & \multicolumn{3}{|c|}{$\begin{array}{c}\text { Concentração nas placas de } \\
\text { vidro recobertas com dióxido } \\
\text { de titânio }(\%)\end{array}$} \\
\hline & ANT & CRI & BZK & ANT & CRI & BZK & ANT & CRI & BZK \\
\hline 0 & 100,0 & 100,0 & 100,0 & 100,0 & 100,0 & 100,0 & 100,0 & 100,0 & 100,0 \\
\hline 20 & 54,3 & 100,0 & 100,0 & 72,0 & 89,9 & 81,9 & 43,0 & $*$ & $*$ \\
\hline 30 & 54,2 & 100,0 & 100,0 & 66,4 & 62,0 & 55,3 & 9,0 & 56,5 & 46,6 \\
\hline 60 & 18,1 & 100,0 & 100,0 & 41,8 & 56,6 & $*$ & 7,8 & 51,5 & 41,7 \\
\hline 180 & 0,75 & 77,8 & 86,2 & 35,8 & 15,8 & 15,8 & 1,5 & 1,21 & 2,10 \\
\hline
\end{tabular}

\footnotetext{
* - medida não realizada
} 
A análise dos resultados obtidos com o criseno e com o benzo(k)fluoranteno indicam que a sílica mostrou-se pouco eficiente no processo de degradação dos poliaromáticos, quando comparada com a sílica impregnada com dióxido de titânio. Alguns autores relatam uma aceleração desse processo quando os HPAs estão adsorvidos em sílica ${ }^{15,16,18}$, mas esse resultado não foi observado neste estudo.

Estes resultados mostram que a degradação em presença de $\mathrm{TiO}_{2}$ é bastante efetiva após 180 min de exposição ao sol.

\section{CONCLUSÕES}

A deposição de dióxido de titânio sobre a zona de concentração de placas cromatográficas de sílica-gel mostrou-se eficiente para promover a degradação fotocatalítica dos HPAs estudados. A separação cromatográfica do antraceno, benzo(k)fluoranteno e criseno no sistema utilizado pode ser considerada satisfatória para esta finalidade. A fluorescência das substâncias estudadas possibilita o acompanhamento visual do processo de degradação, mas está longe do ideal devido à dificuldade de se perceber pequenas variações de luminosidade ou mesmo em se trabalhar com espécies não luminescentes. O uso de técnicas analíticas de superfície, como a fluorescência induzida por laser e a reflectância difusa, que foram utilizadas neste trabalho apenas qualitativamente, é fundamental para a realização de medidas quantitativas que permitam a obtenção de dados físico-químicos e a estimativa da velocidade dos processos de decaimento com muito maior fidelidade.

A vantagem de se utilizar o $\mathrm{TiO}_{2}$ incorporado à camada de sílica é o fato de ter-se a capacidade de adsorção/absorção da sílica acoplada diretamente ao fotocatalisador e à possibilidade de se fazer separações cromatográficas diretamente sobre a placa em estudo. Amostras contendo centenas de mg de HPAs poderiam ser processadas utilizando-se placas preparativas ou semi-preparativas. Isto não seria possível com uma camada contendo apenas o dióxido de titânio. Os resultados obtidos indicam que a sílica não tem grande influência sobre a decomposição das substâncias estudadas, comprovam que os hidrocarbonetos policíclicos aromáticos são rapidamente oxidados quando expostos à radiação ultravioleta na presença de dióxido de titânio e abrem perspectivas para o desenvol- vimento de procedimentos para captação destas substâncias em amostras ambientais contaminadas, bem como da destruição destas substâncias presentes adsorvidas em sílica.

\section{AGRADECIMENTOS}

Os autores agradecem ao Prof. A. Scofield pelas análises realizadas e ao CNPq pelo suporte financeiro. J. C. Moreira, M. M. Higarashi, L. F. V. Ferreira e A. S. Oliveira. agradecem o apoio financeiro do convênio ICCTI/CAPES. A. S. Oliveira agradece à Fundação para a Ciência e Tecnologia a bolsa de Post-Doc. (BPD SFRH/BPD/3650/2000).

\section{REFERÊNCIAS}

1. Bolstrom, C-E.; Gerde, P.; Hanberg, A.; Jernstrom, B.; Johansson, C.; Kyrklund, T.; Rannug, A.; Tornqvist, M.; Victorin, K.; Westertholm, R.; Environ. Health Perspect. 2002 110, suppl 3, 451.

2. http://www.iarc.fr, acessada em Março 2002.

3. Ferreira, M. M. C.; Chemosphere 2001, 44, 125.

4. Higarashi, M. M.; Moreira, J. C.; Ferreira, L. F. V.; Química 2000, 79, 16

5. Nogueira, R. F. P; Jardim, W. F.; Quim. Nova 1998, 21, 69.

6. Ziolli, R. L.; Jardim, W. F.; Quim. Nova 1998, 21, 319

7. Sauer, M. L.; Ollis, D.F.; Hale, M. A.; J. Photochem. Photobiol. A 1995, $88,169$.

8. Tapalov, A.; Molnár-Gábor, D.; Csanádi, J.; Water Res. 1999, 6, 1371.

9. Gálvez, J. B.; Rodrigues, S. M.; Tecnologia de Fotocatálisis solar. Utilización de la Radiación solar para el tratamiento de contaminantes industriales, Cuadernos Monográficos: Almería: España, 1996,

10. Oliveira, A. S.; Fernandes, M. B.; Moreira, J. C.; Ferreira, L. F. V.; J. Braz. Chem. Soc. 2002, 13, 245.

11. Pramauro, E.; Prevot, A.B.; Vicenti, M.; Gamberine, R.; Chemosphere 1998, 36, 1523 .

12. Mallakin, A.; Dixon, G.D; Greenberg, B. M.; Chemosphere 2000, 40, 1435.

13. Stahl, E.; Thin Layer Chromatography: A laboratory Handbook, SpringerVerlag Publisher: New York, 1969

14. Bodzek, D.; Dobosz, C.; Janoszka; B.; Bodzek, P.; J. Planar ChromatogrMod. TLC 1999, 12, 140.

15. Inscoe, M. N.; Anal. Chem, 1964, 36, 2505.

16. Seifert, B.; J. Chromatogr. 1977, 131, 417.

17. Kondo, M. M.; Orlanda, J. F. F.; Ferreira, M. G. A. B.; Grassi, M. T.; Quim. Nova 2003, 26, 133

18. Chang, H. T.; WU, N-M.; Zhu, F.; Water. Res. 2000, 2, 407. 